\title{
Sepsis-related hospital admissions and ambient air pollution: a time series analysis in 6 Chinese cities
}

Yu Wang ${ }^{1 \dagger}$, Zhen Liu ${ }^{2 \dagger}$, Lian Yang ${ }^{3^{*+}}$, Jiushun Zhou ${ }^{4^{*}}$, Jia Li $^{5}$, Hai Lun Liao ${ }^{3}$ and Xing Jun Tian ${ }^{6}$

\begin{abstract}
Background: Some prevalent but rarely studied causes of hospital admissions, such as sepsis is still unknown whether affected by air pollution.

Methods: We used time-series regression within generalized additive models to estimate the effect of air pollutant level on the sepsis-related hospital admissions, for the years 2017-18, using data from six cities in Sichuan, China. Potential effect modifications by age and sex were also explored. The effects of air pollutant on hospital stays for sepsis were also quantified.

Results: Positive associations between short-term exposure to $\mathrm{NO}_{2}$ and $\mathrm{O}_{3}$ and risk of sepsis-related hospital admissions and stays were found. Each $10 \mu \mathrm{g} / \mathrm{m}^{3}$ increase in short-term $\mathrm{NO}_{2}$ at lag 03 and $\mathrm{O}_{3}$ at lag 4 was associated with an increase of $2.76 \%$ (95\% Cl: $0.67,4.84 \%)$ and $0.64 \%$ (95\% Cl: $0.14,1.14 \%)$ hospital admissions, respectively. An increase of $0.72 \%(95 \% \mathrm{Cl}: 0.05,1.40 \%)$ hospital stay was associated with $10 \mu \mathrm{g} / \mathrm{m}^{3}$ increase in $\mathrm{O}_{3}$ concentration at lag 4. Besides, the adverse effect of exposure to $\mathrm{NO}_{2}$ was more significant in males and population aged less than 14 years; while more significant in females and population aged $14 \sim 65$ and over 65 years for exposure to $\mathrm{O}_{3}$. These associations remained stable after the adjustment of other air pollutants.8.

Conclusion: Exposure to ambient $\mathrm{NO}_{2}$ and $\mathrm{O}_{3}$ may cause substantial sepsis hospitalizations, and hospital stays in Sichuan, China. These associations were different in subgroup by age and sex.
\end{abstract}

Keywords: Sepsis, Air pollution, Hospital admission, Time series, China

\section{Background}

During the past two decades, the body of evidence regarding the hazardous effect of ambient air pollution on public health has grown substantially, including particulate matter with aerodynamic diameter $\leq 2.5 \mu \mathrm{m}\left(\mathrm{PM}_{2.5}\right)$ and $\leq 10 \mu \mathrm{m}\left(\mathrm{PM}_{10}\right)$, nitrogen dioxide $\left(\mathrm{NO}_{2}\right)$, ozone $\left(\mathrm{O}_{3}\right)$

\footnotetext{
*Correspondence: yyanglian@163.com; zzzzjs@hotmail.com

${ }^{\dagger}$ Yu Wang and Zhen Liu contributed equally to this work as co-first authors.

'Lian Yang and Jiushun Zhou contributed equally to this work as corresponding authors.

${ }^{3}$ School of Public Health, Chengdu University of Traditional Chinese Medicine, Chengdu 610075, China

${ }^{4}$ Sichuan Center for Disease Control and Prevention, Chengdu 610041, China Full list of author information is available at the end of the article
}

and sulphur dioxide $\left(\mathrm{SO}_{2}\right)$ and carbon monoxide $(\mathrm{CO})$. Our study design was informed by the strong association between air pollution, and multi-organ diseases and injury, including cardio-respiratory disease, stroke, genitourinary diseases, and gastrointestinal diseases [1-3].

Sepsis is a severe syndrome of systemic inflammatory response with a proven or suspected infectious etiology. Severe sepsis is associated with organ dysfunction distant from the site of infection, and may be accompanied by shock. It could be triggered by microbial infection such as pneumonia, kidney infection, cellulitis, and meningitis [4]. In 2017, 48 million cases of sepsis were recorded globally, including 11 million sepsis related

C C The Author(s). 2021 Open Access This article is licensed under a Creative Commons Attribution 4.0 International License, which permits use, sharing, adaptation, distribution and reproduction in any medium or format, as long as you give appropriate credit to the original author(s) and the source, provide a link to the Creative Commons licence, and indicate if changes were made. The images or other third party material in this article are included in the article's Creative Commons licence, unless indicated otherwise in a credit line to the material. If material is not included in the article's Creative Commons licence and your intended use is not permitted by statutory regulation or exceeds the permitted use, you will need to obtain permission directly from the copyright holder. To view a copy of this licence, visit http://creativecommons.org/licenses/by/4.0/ The Creative Commons Public Domain Dedication waiver (http://creativecommons.org/publicdomain/zero/1.0/) applies to the data made available in this article, unless otherwise stated in a credit line to the data. 
deaths, accounting for $19.7 \%$ of all deaths worldwide [5]. A recent study conducted by Christopher, et al. demonstrated that higher level of $\mathrm{PM}_{2.5}$ may increase the intensive care unit (ICU) mortality in patients with sepsis [6]. They believed that larger studies are required to determine if the frequency of ICU admissions is positively associated with short-term exposure to air pollution. The impact of chronic exposure to air pollution on sepsisrelated mortality was explored among 444,928 patient who met the Angus definition of sepsis [7]. In this study, $\mathrm{O}_{3}$ but not $\mathrm{PM}_{2.5}$ air pollution was associated with higher risk of mortality in patients with sepsis, which is not consistent with Christopher's findings. A nested case-control study based on an ongoing national longitudinal cohort, evaluated the effect of $\mathrm{PM}_{2.5}$ on risk of sepsis hospitalization [8]. The results showed that $\mathrm{PM}_{2.5}$ air pollution exposure was not associated with risk of sepsis.

While multiple air pollutants has been associated with health complications, studies evaluating the impact of chronic exposure to air pollution on sepsis is still mixed and limited. To our knowledge no prior study has evaluated the associations between sepsis hospitalization and air pollutants except $\mathrm{O}_{3}$ and $\mathrm{PM}_{2.5}$. Besides, there has been no systematic research on the effect of multi-urban agglomeration and multipollutant on the sepsis. All of these point together towards a need for a comprehensive understanding of the effects on sepsis induced by short-term air pollution exposure.

In southwest China, nearby Sichuan basin and the hengduan mountains, the Sichuan region is one of China's most polluted region. It may be caused by the basin and the surrounding plateau alpine terrain, atmospheric pollutant dispersion degree is relatively slow. Though the total area in Sichuan region account for only $2.7 \%$ in China, the $\mathrm{PM}_{2.5}, \mathrm{NO}_{2}, \mathrm{SO}_{2}$ emissions occupy respectively accounted for $8.3,12.1,5.8 \%$ of the whole of China $[9,10]$. Nearly 100 million in Sichuan region may suffer from air pollutants. Thus, the purpose of this study is to evaluate the impact of short-term exposure to air pollutants $\left(\mathrm{PM}_{2.5}, \mathrm{PM}_{10}, \mathrm{SO}_{2}, \mathrm{NO}_{2}\right.$, and $\left.\mathrm{O}_{3}\right)$ on sepsis hospitalizations in 6 cities of Sichuan region from January 1, 2017 to January 1, 2019.

\section{Methods}

\section{Study setting}

A multi-stage stratified cluster sampling method was used to extract samples from medical and health institutions. In the first stage, according to the sampling principles such as the level of economic and health services, and geographical location the Sichuan region, six cities were selected in our study. Cities of plain areas include

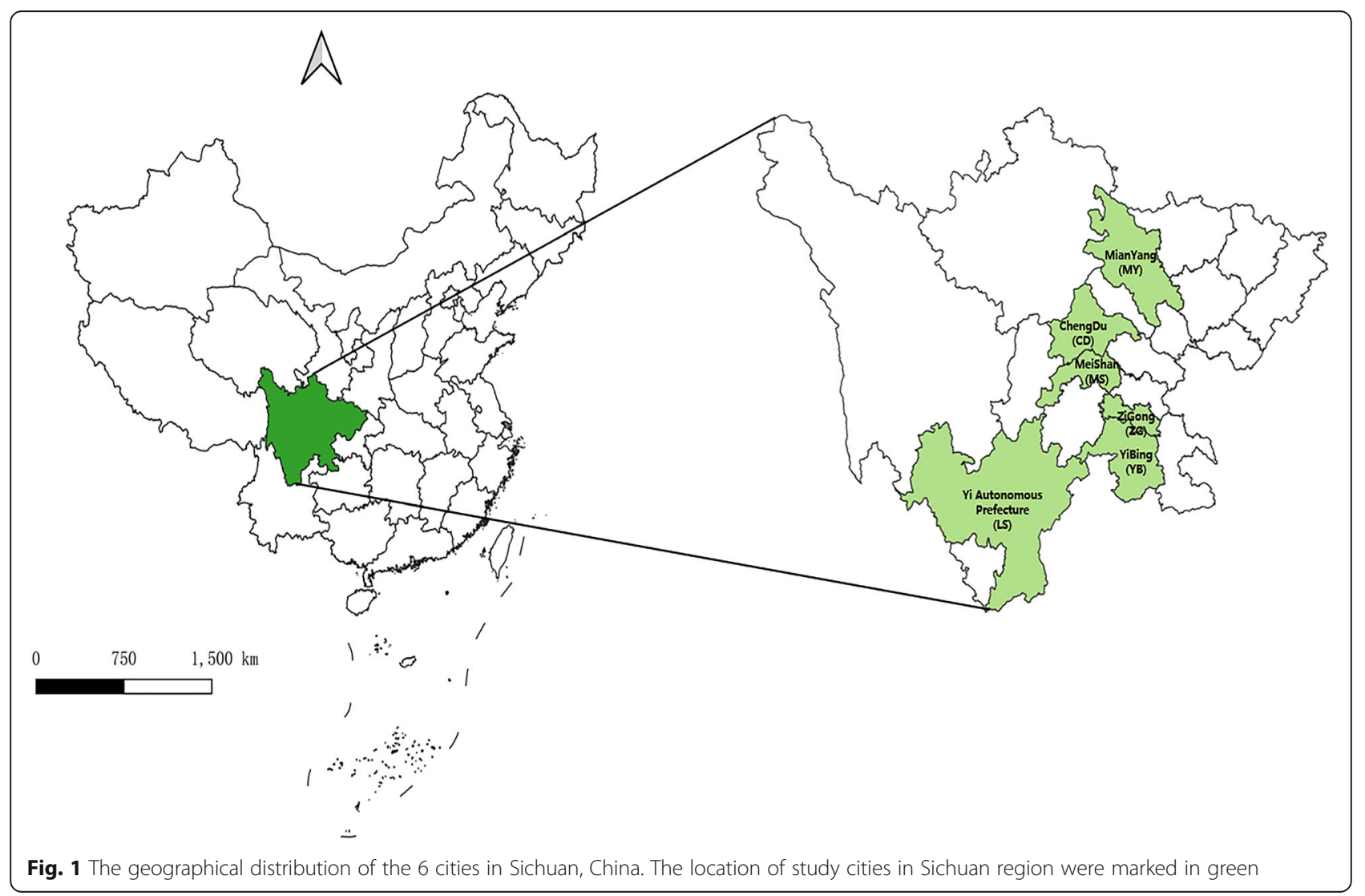


Chengdu (CD), Meishan (MS), hilly areas include Mianyang (MY), Yibin (YB), Zigong (ZG), and plateau areas include Yi Autonomous Prefecture (LS). The geographical distributions of the six cities in Sichuan, China were displayed in Fig. 1.

In the second stage, 4 counties (districts) are selected from each city as the sample counties (districts). In the third stage, general hospitals, traditional Chinese medicine hospitals, specialized hospitals, maternity and child care hospitals and some primary medical and health institutions will be selected from each sample county (district). Records of the electronic medical information system were extracted from all the medical health institutions in the 6 cities. A total of 412 medical and health institutions were involved. The population covered in this study exceeded 35 million, and the proportion of inpatients included accounted for more than $80 \%$ of the inpatients in all medical and health institutions of the studied cities.

\section{Environmental data}

Ambient air quality data were collected from the China National Environmental Monitoring Center and Department of Ecology and Environment of Sichuan Province. Hourly concentrations of $\mathrm{PM}_{10}, \mathrm{PM}_{2.5}, \mathrm{NO}_{2}, \mathrm{SO}_{2}, \mathrm{O}_{3}$, and $\mathrm{CO}$ were measured from 67 air monitoring stations interspersed in the 6 cities: 19 in CD, 6 in MS, 9 in MY, 10 in YB, 6 in ZG, and 17 in LS. The daily 24-h mean concentration of air pollution was simply averaged of all valid sites in each city for analyses. To adjust the impact of weather conditions, meteorological data including daily mean temperature and relative humidity were obtained from the Department of Ecology and Environment of Sichuan Province.

\section{Hospital admissions data}

We diagnosed sepsis as the life-threatening organ dysfunction caused by dysregulated response to infection, and only required suspected infection rather than proven one [11]. Overall sepsis estimates were based on both explicit and implicit with organ dysfunction codes, according to the approach used in epidemiology studies of sepsis $[5,12]$. The cases diagnosed as both International Classification of Diseases 10th and 9th Revision Code (ICD-10 and ICD-9) referencing sepsis explicitly were explicit sepsis; cases could not meet criteria for explicit sepsis but with the code of organ dysfunction was eligible to be classified as implicit sepsis with organ dysfunction group. Detailed ICD-10 and ICD-9 codes for the identification of explicit sepsis and implicit sepsis were listed in the Table S1.

Some patients suffered the sepsis during the period of the hospitalization. We only collected the sepsis patients with the primary admission diagnosis, which were more vulnerable to air pollutants before admissions. The sepsis data was obtained from the electronic medical information system of 412 medical and health institutions. After desensitization, the basic characteristics of the patients and the information of medical treatment were obtained.

\section{Statistical analysis}

The original data manipulation was performed using SAS version 10.4, to obtain the daily hospital admissions, daily-average air pollutant concentration and meteorological level. To avoid the bias, and provided the most realistic daily air pollutant exposure on population, residential postcode of patients was used to match sepsis episodes and link with air pollution data, rather than the hospital postcode. Then we applied a two-stage analytical approach to estimate the city-specific and multicities average associations between daily air pollution levels and sepsis-related hospital admissions.

In the first stage, since daily hospital admissions approximately followed a quasi-Poisson distribution, we used generalized additive models (GAM) to estimate the city-specific short-term effects of air pollution. Several covariates were adjusted in the main models as a standardized protocol in time-series analyses [13-15]: 1) a natural spline function of calendar time with 7 degrees of freedom (df) per year to account for potential temporal trends in hospitalizations; 2 ) a dummy variable for days of week to eliminate the weekday effect; 3 ) a natural spline function of present-day average temperature and relative humidity with respective $6 \mathrm{dfs}$ and $3 \mathrm{dfs}$ to account for potential confounding effects of weather factors [13-15]. Briefly, the main model is as follows: $\log \left[E\left(Y_{t}\right)\right]=\alpha+D O W+\mathrm{Z}_{t}+n s($ day, $d f)+n s($ temperature, $d f)+n s\left(\right.$ relative humidity), where $\mathrm{E}\left(\mathrm{Y}_{\mathrm{t}}\right)$ indicates the estimated number of hospital admissions for sepsis on day $\mathrm{t} ; \mathrm{Z}_{\mathrm{t}}$ denotes the air pollutant concentrations on day $\mathrm{t}$; $\mathrm{ns}$ is a natural spline function; $\mathrm{df}$ is the degrees of freedom; DOW is the dummy variable for day of the week, and $\alpha$ is the intercept.

In the second stage, random-effects meta-analyses were applied to combine the city-specific estimates to pool the average estimates at a regional level $[16,17]$. To search the lag patterns in the impacts of air pollutants on sepsis, we further introduced both single-day lags and moving average lag days, using the same models. Single-day lag structures (lag 0 to lag 7) were the days before the hospital admissions. For example, lag 0 is the current day of hospital admission; lag 1 and lag 2 is the 1 day before admission and 2 days before admission. The moving average lag days were cumulative lag effects of air pollutants effects from lag 01 to lag 06 days. For example, lag 01 was the 2-day moving average concentration computed as the means of lag 0 and lag 1 days; lag 06 was the 7-day moving average concentration computed as the means of from lag 0 to lag 6 days. 
We further conducted stratified analyses by sex, and age groups $(0 \sim 13$ years; $14 \sim 65$ years; $>65$ years $)$ to explore the potential effect modifications among different population. Sensitivity analyses were conducted to assess the stability and robustness of the estimates in twopollutant models. Two-pollutant models aimed to adjust the other air pollutants using the same parameter settings as in the main mode. Furthermore, we also analyzed the association between the hospital stay of sepsis and short-term exposure to air pollutants which had significant effects on hospitalizations. Since days of hospitalization displayed a similar distribution with daily hospitalizations, the same model setting was used to fit associations of air pollution with hospital stays [18].

All analyses were conducted in $\mathrm{R}$ version 3.4.1 ( $\mathrm{R}$ Foundation for Statistical Computing, Vienna, Austria), with the "mgcv" package and "rmeta" package. The estimates are reported as percentage changes and 95\% confidence intervals $(95 \% \mathrm{CI})$ in daily sepsis-related hospital admissions associated with per $10 \mu \mathrm{g} / \mathrm{m}^{3}$ increase in air pollutant concentrations. A two-sided alpha level of 0.05 $(P$-value $<0.05)$ was considered statistically significant.

\section{Results}

\section{Descriptive results}

From the medical records from 6 large cities in Sichuan, China, 58,064 hospital admissions for sepsis occurred from 1st January 2017 to 31st December 2018 (731 days). Overall, there were $57.4 \%$ female patients and $49.8 \%$ patients aged 14 65 years. The daily average values of hospital stays and hospitalizations for sepsis were 119 days and 13 cases, respectively. Daily concentrations of air pollutants were comparatively low during the study period, with a daily average of 41.4, 63.8, 12.1, 25.3, $82.7 \mu \mathrm{g} / \mathrm{m}^{3}$ for $\mathrm{PM}_{2.5}, \mathrm{PM}_{10}, \mathrm{NO}_{2}, \mathrm{SO}_{2}, \mathrm{O}_{3}$, and 0.8 $\mathrm{mg} / \mathrm{m}^{3}$ for $\mathrm{CO}$, compared with the air quality guideline for limit of pollutant concentration in China (Table S2). The daily average temperature and relative humidity were $17.5^{\circ} \mathrm{C}$ and $76.3 \%$, respectively. More detailed information for these descriptive statistics with sepsis can be found in Table 1 .

\section{GAM results}

Table 2 presented the percentage change of sepsis hospitalizations associated with the increases of different air pollutants level. We found that $\mathrm{NO}_{2}$-sepsis associations were significant at the current day (lag 0 ), lag 1 , and lag 01 to lag 04, with the largest estimates of $2.76 \%$ (95\% CI: $0.67,4.84 \%)$ at lag 03 . The increase of $\mathrm{O}_{3}$ concentration were also statistically significant related with the sepsis hospitalizations at lag 3, lag 4 and lag 7, and the largest estimates was $0.64 \%$ (95\% CI: $0.14,1.14 \%)$ at lag 4 . The city-specific associations between $\mathrm{NO}_{2}, \mathrm{O}_{3}$ and sepsisrelated hospital admissions have been supplemented in the Table S3.

Table 1 Summary statistics of data on hospital admissions and stays of sepsis, air pollutants, and weather conditions in 6 Sichuan cities, 2017-18

\begin{tabular}{|c|c|c|c|c|c|c|c|}
\hline & Number (\%) & Mean & SD & MIN & Median & MAX & Range \\
\hline \multicolumn{8}{|c|}{ Hospital admissions of sepsis } \\
\hline total & 58,064 & 13 & 9 & 7 & 11 & 30 & 23 \\
\hline $0 \sim 13$ years & $16,325(28.1 \%)$ & 4 & 3 & 1 & 3 & 9 & 7 \\
\hline $14 \sim 65$ years & $28,905(49.8 \%)$ & 7 & 4 & 4 & 5 & 14 & 10 \\
\hline$>65$ years & $12,834(22.1 \%)$ & 3 & 2 & 0 & 3 & 8 & 7 \\
\hline male & $24,764(42.6 \%)$ & 6 & 4 & 3 & 5 & 13 & 10 \\
\hline female & $33,300(57.4 \%)$ & 8 & 5 & 4 & 6 & 17 & 12 \\
\hline Hospital stays of sepsis & & 119 & 88 & 57 & 91 & 288 & 231 \\
\hline \multicolumn{8}{|c|}{ 24-h average air pollutant concentrations, $\mu \mathrm{g} / \mathrm{m}^{3}$} \\
\hline $\mathrm{PM}_{2.5}$ & & 41.4 & 13.2 & 17.6 & 45.0 & 54.9 & 37.3 \\
\hline $\mathrm{PM}_{10}$ & & 63.8 & 15.9 & 35.0 & 67.4 & 77.8 & 42.8 \\
\hline $\mathrm{NO}_{2}$ & & 12.1 & 3.6 & 8.2 & 11.1 & 18.4 & 10.2 \\
\hline $\mathrm{SO}_{2}$ & & 25.3 & 7.8 & 12.9 & 25.9 & 36.8 & 23.8 \\
\hline $\mathrm{O}_{3}$ & & 82.7 & 7.9 & 74.1 & 82.8 & 93.0 & 18.9 \\
\hline $\mathrm{CO}$ & & 0.8 & 0.1 & 0.6 & 0.8 & 0.9 & 0.3 \\
\hline \multicolumn{8}{|c|}{ 24-h average weather conditions } \\
\hline temperature & & 17.5 & 1.2 & 15.5 & 17.6 & 18.8 & 3.4 \\
\hline relative humidity & & 76.3 & 5.2 & 66.9 & 78.0 & 81.7 & 14.9 \\
\hline
\end{tabular}

Abbreviations: SD standard deviation; MIN minimal; MAX maximal 
Table 2 Percentage increase (estimates and 95\% Cl) in daily hospital admissions of sepsis associated with $10-\mu \mathrm{g} / \mathrm{m}^{3}$ increase in $\mathrm{PM}_{10}, \mathrm{PM}_{2.5}, \mathrm{SO}_{2}, \mathrm{NO}_{2}, \mathrm{O}_{3}$ and $1 \mathrm{mg} / \mathrm{m}^{3} \mathrm{CO}$ concentrations in different lag days and moving average days in 6 Sichuan cities

\begin{tabular}{|c|c|c|c|c|c|c|}
\hline Lag days & $\mathrm{PM}_{10}$ & $\mathrm{PM}_{2.5}$ & $\mathrm{SO}_{2}$ & $\mathrm{NO}_{2}$ & $\mathrm{O}_{3}$ & $\mathrm{CO}$ \\
\hline $\operatorname{lag} 0$ & $-0.04(-0.57,0.48)$ & $-0.33(-1.15,0.49)$ & $1.69(-5.52,8.89)$ & $2.54(0.24,4.85)$ & $-0.62(-1.25,0.01)$ & $7.25(-1.24,15.70)$ \\
\hline $\operatorname{lag} 1$ & $-0.08(-0.51,0.35)$ & $-0.13(-1.00,0.74)$ & $-0.05(-6.65,6.54)$ & $1.66(0.11,3.21)$ & $-0.18(-0.61,0.25)$ & $6.43(-1.85,14.70)$ \\
\hline $\operatorname{lag} 2$ & $-0.19(-0.60,0.22)$ & $-0.16(-0.99,0.68)$ & $0.64(-4.10,5.39)$ & $1.29(-0.24,2.82)$ & $0.06(-0.32,0.45)$ & $6.32(-3.99,16.60)$ \\
\hline $\operatorname{lag} 3$ & $-0.03(-0.52,0.46)$ & $-0.07(-0.91,0.77)$ & $0.43(-3.47,4.34)$ & $0.77(-0.73,2.27)$ & $0.44(0.07,0.82)$ & $6.05(-1.66,13.80)$ \\
\hline $\operatorname{lag} 4$ & $-0.09(-0.43,0.25)$ & $-0.22(-0.79,0.35)$ & $0.57(-2.80,3.93)$ & $-0.04(-1.51,1.43)$ & $0.64(0.14,1.14)^{a}$ & $3.23(-5.40,11.90)$ \\
\hline lag5 & $-0.16(-0.49,0.18)$ & $-0.40(-0.86,0.07)$ & $1.06(-2.28,4.41)$ & $0.00(-1.46,1.46)$ & $0.17(-0.19,0.54)$ & $-2.49(-9.37,4.40)$ \\
\hline $\operatorname{lag} 6$ & $0.06(-0.37,0.48)$ & $-0.06(-0.56,0.44)$ & $2.20(-1.78,6.17)$ & $-0.17(-1.97,1.63)$ & $0.27(-0.16,0.70)$ & $0.12(-8.43,8.66)$ \\
\hline $\operatorname{lag} 7$ & $0.11(-0.22,0.45)$ & $-0.01(-0.46,0.45)$ & $1.43(-3.09,5.94)$ & $-1.00(-2.78,0.78)$ & $0.48(0.02,0.94)$ & $1.27(-7.07,9.60)$ \\
\hline lag01 & $-0.08(-0.66,0.49)$ & $-0.32(-1.31,0.68)$ & $0.70(-7.84,9.23)$ & $2.41(0.68,4.15)$ & $-0.54(-1.15,0.08)$ & $8.66(-0.90,18.20)$ \\
\hline lag02 & $-0.17(-0.70,0.36)$ & $-0.34(-1.44,0.76)$ & $0.91(-8.31,10.10)$ & $2.66(0.74,4.57)$ & $-0.31(-0.93,0.32)$ & $11.00(-1.27,23.30)$ \\
\hline $\operatorname{lag} 03$ & $-0.15(-0.76,0.46)$ & $-0.33(-1.63,0.96)$ & $0.85(-8.60,10.30)$ & $2.76(0.67,4.84)^{a}$ & $0.09(-0.55,0.73)$ & $13.70(-0.18,27.50)$ \\
\hline lag04 & $-0.16(-0.85,0.52)$ & $-0.41(-1.88,1.05)$ & $1.59(-7.25,10.40)$ & $2.51(0.26,4.75)$ & $0.41(-0.26,1.07)$ & $14.20(-1.93,30.40)$ \\
\hline ag05 & $-0.29(-0.89,0.32)$ & $-0.62(-1.98,0.75)$ & $1.98(-7.28,11.20)$ & $2.28(-0.12,4.69)$ & $0.48(-0.21,1.18)$ & $10.90(-5.40,27.20)$ \\
\hline $\operatorname{lag} 06$ & $-0.28(-0.95,0.39)$ & $-0.67(-2.07,0.73)$ & $2.91(-6.18,12.00)$ & $2.03(-0.53,4.59)$ & $0.60(-0.12,1.32)$ & $9.50(-8.52,27.50)$ \\
\hline
\end{tabular}

Note: Statistically significant estimates were marked in bold; ${ }^{a}$ the largest estimate in all lag period

There was also statistically significant association between $\mathrm{O}_{3}$ level and sepsis hospital stay at the lag 3, lag 4 and lag 7 (Table 3). An increase of $10 \mu \mathrm{g} / \mathrm{m}^{3}$ of $\mathrm{O}_{3}$ at lag 04 was associated with $0.72 \%$ (95\% CI: $0.05,1.40 \%)$ increase in hospital stay for sepsis. However, we didn't observe any statistically significant associations between $\mathrm{NO}_{2}$ and hospital stay for sepsis.

Table 3 Percentage increase (estimates and 95\% Cl) in hospital stay associated with $10-\mu \mathrm{g} / \mathrm{m}^{3}$ increase in $\mathrm{NO}_{2}$ and $\mathrm{O}_{3}$ concentrations in different lag days and moving average days in 6 Sichuan cities

\begin{tabular}{lll}
\hline lag days & $\mathrm{NO}_{\mathbf{2}}$ & $\mathbf{O}_{\mathbf{3}}$ \\
\hline lag0 & $0.73(-3.80,5.27)$ & $-0.71(-1.69,0.27)$ \\
lag1 & $0.21(-1.98,2.39)$ & $-0.42(-1.03,0.19)$ \\
lag2 & $-0.44(-2.60,1.72)$ & $0.13(-0.57,0.82)$ \\
lag3 & $-0.93(-3.20,1.34)$ & $\mathbf{0 . 6 7}(\mathbf{0 . 0 5}, \mathbf{1 . 2 9})$ \\
lag4 & $-1.74(-3.80,0.32)$ & $\mathbf{0 . 7 2}(\mathbf{0 . 0 5}, \mathbf{1 . 4 0})^{\mathbf{a}}$ \\
lag5 & $0.07(-1.98,2.12)$ & $0.17(-0.35,0.68)$ \\
lag6 & $0.51(-1.52,2.53)$ & $0.37(-0.14,0.88)$ \\
lag7 & $0.21(-2.00,2.42)$ & $\mathbf{0 . 7 3}(\mathbf{0 . 2 2}, \mathbf{1 . 2 3})$ \\
lag01 & $0.05(-4.14,4.23)$ & $-0.79(-1.68,0.09)$ \\
lag02 & $0.04(-3.63,3.71)$ & $-0.51(-1.40,0.39)$ \\
lag03 & $-0.04(-3.63,3.54)$ & $0.15(-0.88,1.17)$ \\
lag04 & $-0.68(-3.82,2.47)$ & $0.60(-0.55,1.75)$ \\
lag05 & $-0.74(-4.10,2.62)$ & $0.65(-0.47,1.77)$ \\
lag06 & $-0.79(-4.36,2.78)$ & $0.70(-0.32,1.72)$ \\
\hline
\end{tabular}

Note: Statistically significant estimates were marked in bold; ${ }^{a}$ the largest estimate in all lag period

\section{Stratified and sensitive analyses}

As the GAM results showed that only $\mathrm{NO}_{2-}$ and $\mathrm{O}_{3-}$ sepsis associations were significant at the current day and lag days, the results of stratified analyses and effects on the hospital stay of sepsis were displayed only for $\mathrm{NO}_{2}$ and $\mathrm{O}_{3}$. The stratified analyses of other air pollutants were supplemented in the Table S4. Multi-cities estimates of the associations between hospital admissions for sepsis and the two air pollutants $\left(\mathrm{NO}_{2}\right.$ and $\left.\mathrm{O}_{3}\right)$ stratified by age and sex were displayed in Fig. 2. We conducted stratified and sensitive analyses at the lag days which generated the highest estimates in basic models for total populations.

The percentage increases of hospital admissions for sepsis associated with $\mathrm{NO}_{2}$, were statistically significant and positive for males and people aged $0 \sim 13$ years. While for $\mathrm{O}_{3}$, the estimated associations were statistically significant for females, people aged $14 \sim 65$ and $>65$ years.

Table 4 presented the results of the two-pollutant models to exclude the confounding effects by other air pollutants. The effect estimates remained even unchanged when we adjusted the co-pollutants in the models for $\mathrm{O}_{3}$. Besides, the estimated effect of $\mathrm{NO}_{2}$ were strengthened, especially with particulate matter adjustments. The $\mathrm{NO}_{2}$-related percentage increases for sepsis hospitalizations at lag 03 days were 5.03\% (95\% CI: 1.42, 8.65 ) and $4.41 \%$ (95\% CI: $1.98,6.84)$ in two-pollutant models adjusted for $\mathrm{PM}_{10}$ and $\mathrm{PM}_{2.5}$, respectively.

\section{Discussion}

This study assessed the relationship between sepsis hospital admissions and stays and short-term exposure to 


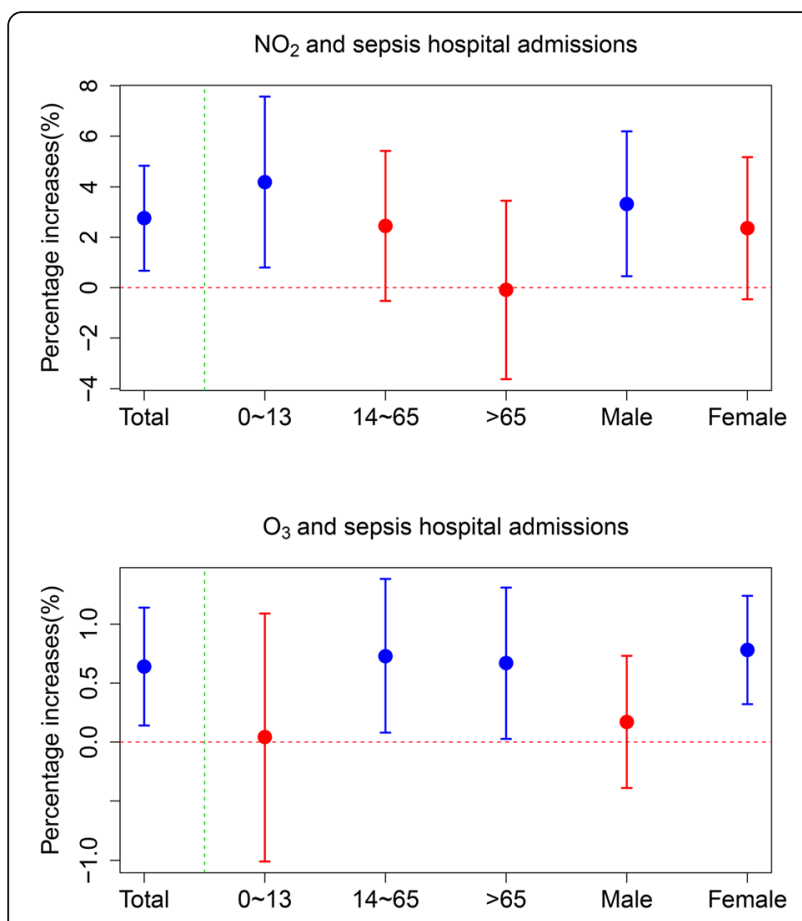

Fig. 2 Percentage increase (estimates and $95 \% \mathrm{Cl}$ ) in daily hospital admissions of sepsis associated sepsis of $10-\mu \mathrm{g} / \mathrm{m}^{3}$ increase in $\mathrm{NO}_{2}$ and $\mathrm{O}_{3}$ concentrations at lag days with the highest estimates of basic models for total populations, stratified by age and sex

six main air pollutants at a multi-city level. We found that increased sepsis-related hospital admission and stay were associated with short-term exposure to $\mathrm{NO}_{2}$ and $\mathrm{O}_{3}$. The lag patterns which generated the most pronounced effect of $\mathrm{NO}_{2}$ and $\mathrm{O}_{3}$ differed. Risks of hospital admission for sepsis per $\mathrm{NO}_{2}$ and $\mathrm{O}_{3}$ concentration increase were different in subgroups by age and sex. Our results support the hypothesis that the sepsis population is affected by air pollutants and warrants further study.

In this study, we estimated percentage increases in hospital admissions and stays for sepsis associated with increase in each air pollutant concentration using a time-series analysis at a 6 large cities level. This time-

Table 4 Percentage increase (estimates and 95\% Cl) in daily hospital admissions of sepsis associated sepsis of $10-\mu \mathrm{g} / \mathrm{m}^{3}$ increase in $\mathrm{NO}_{2}$ and $\mathrm{O}_{3}$ concentrations in lag days with largest estimates, with adjustment of different co-pollutants

\begin{tabular}{lll}
\hline & $\mathrm{NO}_{2}$ & $\mathbf{O}_{3}$ \\
\hline Single air pollutant model & $2.76(0.67,4.84)$ & $0.64(0.14,1.14)$ \\
Adjusted for $\mathrm{PM}_{2.5}$ & $5.03(1.42,8.65)$ & $0.65(0.13,1.16)$ \\
Adjusted for $\mathrm{PM}_{10}$ & $4.41(1.98,6.84)$ & $0.64(0.14,1.15)$ \\
Adjusted for $\mathrm{CO}$ & $2.58(0.30,4.86)$ & $0.67(0.16,1.18)$ \\
Adjusted for $\mathrm{SO}_{2}$ & $2.72(1.07,4.37)$ & $0.65(0.18,1.13)$ \\
Adjusted for $\mathrm{O}_{3}$ or $\mathrm{NO}_{2}$ & $3.20(1.08,5.32)$ & $0.49(0.21,0.76)$ \\
\hline
\end{tabular}

series analysis has been developed and wildly used to explore the harmful health effect induced by air pollutants on mortality or disease-specific hospital admissions and visits of various diseases $[19,20]$. They may increase the all-cause or non-infectious cardiovascular, and respiratory diseases mortality $[17,21]$ and hospital admissions/ visits [14-16]. New issues of the time-series regression model for infectious disease were also hot and developed, including tuberculosis [22], pneumonia [23, 24], lower respiratory infections [25], inflammatory dermatoses [26]. Little is known about the effect of different air pollution on sepsis hospitalizations specifically from the existing researches. We therefore analysed sepsis based on its high prevalence, limited knowledge, shared biological pathways and nascent associations with pollution [7]. Since air pollution and healthcare resources are distributed unevenly across China and world, it may restrict the validity and generalizability of this study. Nevertheless, these 6 cities from Sichuan region in our study were typical cities in Southwest China, and our study could provide the evidence that air pollution may increase the burden of disease and cost from sepsis.

In our study, the effect estimate on sepsis hospital admission was a $0.64 \%$ increase per $10 \mu \mathrm{g} / \mathrm{m}^{3}$ increase in $\mathrm{O}_{3}$ within 4 days, and $2.76 \%$ increase per $10 \mu \mathrm{g} / \mathrm{m}^{3}$ increase in $\mathrm{NO}_{2}$ at lag 03. The strongest effect of air pollution presented a time lag with regard to air pollution concentrations, while there was also a suggestion for a cumulative effect. Recently, a time stratified, case crossover analyses conducted in the United States found that short-term exposure to $\mathrm{PM}_{2.5}$ is associated with increased risk of hospital admissions due to septicaemia. Absolute increase in risk of admission to hospital of sepsis per 10 million person days associated with per $1 \mu \mathrm{g} /$ $\mathrm{m}^{3}$ increase $\mathrm{PM}_{2.5}$ at lag 01 days was 0.41 (95\% CI: 0.29 , 0.54) [27]. A number of explanations are possible for the difference between our associations and theirs. Their study population is limited to Medicare population without younger populations, while younger patients $(0 \sim 13$ years) suffered sepsis accounted almost one-third in our study, which cannot be ignored. On the other hand, the study period was from 2000 to 2012 in their study, and we observed the data in recent years. A recent study stated that point estimates for $\mathrm{PM}_{2.5}$ and ICU admission were positive, suggesting a potential association exists, but they failed to observed it as statistically significant [6]. We observed all sepsis patients throughout the hospital, besides the ICU, with a larger sample size $(58,064$ sepsis cases versus 10,725 sepsis ICU cases [6]). Another study with 444,928 patients of sepsis also reported that exposure to increased levels of $\mathrm{O}_{3}$ was associated with higher risk of mortality in patients with sepsis [7], while $\mathrm{PM}_{2.5}$ was not associated with sepsis which is similar with our results. For the impact of air pollutants on 
sepsis hospitalization, a nested case-control study also showed no relationship between $\mathrm{PM}_{2.5}$ air pollution and sepsis hospitalization [8]. Therefore, the current evidence of the effect of $\mathrm{PM}_{2.5}$ air pollution on sepsis is insufficient and controversial. In addition to the research on particulate matter, studies on gaseous pollutants $\left(\mathrm{SO}_{2}, \mathrm{NO}_{2}, \mathrm{O}_{3}\right.$ and $\left.\mathrm{CO}\right)$ and sepsis is more scarce. Our results can provide relevant evidence, while need more research results to compare and verify.

From the results in our study, increased $\mathrm{NO}_{2}$ and $\mathrm{O}_{3}$ concentration may increase the number of sepsis cases and prolong the duration of hospitalization. However, sepsis is a prevalent but rarely studied causes of hospital admissions that was identified significant associations with short-term exposure to air pollution. Therefore, the physiological processes affected by the ambient air pollutants for sepsis is unknown. Short-term exposure to pollution has been proved to be associated with multiple infectious diseases, including pneumonia [23, 24], lower respiratory infections [25], inflammatory dermatoses [26] in general hospital populations. Sepsis is a critical syndrome of systemic inflammation triggered by infectious diseases and widespread organ dysfunction. Therefore, the risk of sepsis may increase by various infectious diseases which are associated with the air pollution exposure. The association between air pollution and sepsis is likely to come from the effects of air pollution on infectious diseases, or the combined effect of air pollution and infectious diseases. The pathophysiology may overlap with the damage by short-term exposure of air pollution, and the occurrence of infectious diseases. Therefore, we need to realize that air pollution may increase the incidence of sepsis, but it is not a direct pathogenic factor. The corresponding hospitalization numbers and stays should be interpreted carefully.

Further work in exploring the role air pollution has in the pathophysiology of sepsis could focus on markers of inflammation [28]. Inflammation has many players, including circulating cells and plasma proteins, vascular wall cells, and so on. A large scale study reporting an association between gaseous pollutants and C-reactive protein in diabetic patients [29]. This may explain that the associations were only significant in gaseous pollutants in our study. In our study, total sepsis estimates were based on both explicit and implicit with organ dysfunction codes. While implicit sepsis related to organ dysfunction might be developed gradually and is a chronic process. Short-term effect of air pollutants exposure may increase the sepsis hospitalizations by triggering acute episodes and exacerbations of implicit sepsis. The longterm effect of air pollutants on sepsis should be further studied in the future. We also explored the high-risk groups of different age and sex which were more vulnerable to air pollutant. These effect modification by age and sex was also observed in previous studies [7, 13]. Sepsis might be triggered to hospital admission due to diseases that are positively associated with short-term air pollution, making difference among age and sex groups.

The strengths of this analysis lie in the large number of sepsis cases. Besides, the ability to capture patients from over 6 typical Chinese cities allows for good external validity and generalizability. In addition, we evaluated a new causes of hospital admissions related to both gaseous pollutants and particulate matter that have rarely been studied. Finally, we further explored the effect of ambient air pollution on hospital stays for sepsis, which strengthens our findings.

This study also has some weaknesses. Firstly, we only evaluated the associations between air pollution and sepsis hospital admissions and stays, did not fully capture the corresponding costs associated with air pollution exposure. But we would estimate the economic burden of sepsis attribute to air pollution in the near future. Second, the lack of previous evidence requires further epidemiological studies and investigation of possible underlying mechanisms for this health effect. Finally, in our study, two-years research period is relatively short, and we need a longer time series for further research.

\section{Conclusion}

This current study provide the evidence that exposure to $\mathrm{NO}_{2}$ and $\mathrm{O}_{3}$ may cause increased sepsis hospital admissions and hospital stays in Sichuan, China. Future research is needed to confirm these findings and explore potential mechanisms of the adverse effects of $\mathrm{NO}_{2}$ and $\mathrm{O}_{3}$ pollution in patients with sepsis.

\section{Abbreviations}

$\mathrm{PM}_{25}$ : Particulate matter with aerodynamic diameter $\leq 2.5 \mu \mathrm{m}$;

$\mathrm{PM}_{10}$ : Particulate matter with aerodynamic diameter $\leq 10 \mu \mathrm{m} ; \mathrm{NO}_{2}$ : Nitrogen dioxide; $\mathrm{O}_{3}$ : Ozone; $\mathrm{SO}_{2}$ : Sulphur dioxide; $\mathrm{CO}$ : Carbon monoxide;

ICU: Intensive care unit; CD: Chengdu; MS: Meishan; MY: Mianyang; YB: Yibin; ZG: Zigong; LS: Yi autonomous prefecture; ICD-10: International classification of diseases 10th code; ICD-9: International classification of diseases 9th revision code; GAM: Generalized additive models; Df: Degrees of freedom; 95\% Cl: 95\% Confidence intervals

\section{Supplementary Information}

The online version contains supplementary material available at https://doi. org/10.1186/s12889-021-11220-x.

Additional file1 Table S1. Detailed ICD codes for the identification of sepsis. Table S2. Limit of pollutant concentration and Individual air quality index. Table S3. The city-specific percentage increase (estimates and $95 \% \mathrm{Cl}$ ) in daily hospital admissions of sepsis associated with 10- $\mathrm{\mu g} /$ $\mathrm{m}^{3}$ increase in $\mathrm{NO}_{2}$ and $\mathrm{O}_{3}$ concentrations at lag day with the highest estimates of basic models for total populations. Table S4. Percentage increase (estimates and $95 \% \mathrm{Cl}$ ) in daily hospital admissions of sepsis associated sepsis of $10-\mu \mathrm{g} / \mathrm{m}^{3}$ increase in $\mathrm{PM}_{2.5}, \mathrm{PM}_{10}$ and $\mathrm{SO}_{2}$ concentrations, and $1 \mathrm{mg} / \mathrm{m}^{3}$ increase in $\mathrm{CO}$, stratified by age and sex. 


\section{Acknowledgements}

We wish to thank the Health Commission of Sichuan Province and Sichuan Administration of TCM for supply of sepsis-related hospital admission data. We wish to thank the Department of Ecology and Environment of Sichuan Province for supply Environmental test data. We also would like to thank the anonymous reviewers for their kind comments and valuable suggestions.

\section{Authors' contributions}

$J \mathrm{~L}, \mathrm{HL}$, and $\mathrm{XT}$ were major contributors in collecting the data. $\mathrm{YW}$ and $\mathrm{ZL}$ analyzed the data. JZ supported interpretation of findings. YW and ZL drafted the manuscript. LY reviewed and revised the manuscript. All authors read and approved the final manuscript.

\section{Funding}

This work was supported by the Calculation and Research of Total Health Expenditure in Sichuan Province in 2019; and Spatial Temporal Evolution Characteristics and Factors of Total Health Expenditure in Sichuan Province Based on Spatial Econometric Model (Grant No. 2019JDR0108).

\section{Availability of data and materials}

The datasets generated and/or analysed during the current study are not publicly available due to data sharing regulations but are available from the corresponding author on reasonable request.

\section{Declarations}

\section{Ethics approval and consent to participate}

The ethics Committee of the Affiliated Hospital of Chengdu University of Chinese Medicine approved the study.

All study procedures involving human subjects conform to the ethical standards of the Ethics Committee of the Hospital affiliated to Chengdu University of Traditional Chinese Medicine and the 1964 Helsinki Declaration and its subsequent amendments or similar ethical standards. We had no access to information that could identify individual participants, so our research does not involve patients' personal information and written informed consent was waived by the ethics Committee of the Affiliated Hospital of Chengdu University of Chinese Medicine.

\section{Consent for publication}

Not applicable.

\section{Competing interests}

The authors declare that they have no competing interests

\section{Author details}

${ }^{1}$ Department of Anesthesiology, Union Hospital, Tongji Medical College, Huazhong University of Science and Technology, Wuhan 430022, China. ${ }^{2}$ Second Affiliated Hospital of Chengdu Medical College, China National Nuclear Corporation 416 Hospital, Chengdu 610057, China. ${ }^{3}$ School of Public Health, Chengdu University of Traditional Chinese Medicine, Chengdu 610075, China. ${ }^{4}$ Sichuan Center for Disease Control and Prevention, Chengdu 610041, China. ${ }^{5}$ Management College, Chengdu University of Traditional Chinese Medicine, Chengdu 610032, China. 'Sichuan Administration of TCM, Chengdu 610016, China.

Received: 18 February 2021 Accepted: 28 May 2021

\section{Published online: 21 June 2021}

\section{References}

1. Kelly FJ, Fussell JC. Air pollution and public health: emerging hazards and improved understanding of risk. Environ Geochem Health. 2015;37(4):63149. https://doi.org/10.1007/s10653-015-9720-1.

2. Brunekreef B, Holgate ST. Air pollution and health. Lancet. 2002;360(9341): 1233-42. https://doi.org/10.1016/S0140-6736(02)11274-8.

3. Chen F, Liu Q, Huang B, Huang F, Li Y, Peng Y, et al. Association of fine particulate matter exposure with acute noncardiovascular critical illnesses and in-hospital outcomes in patients receiving intensive cardiac care. BMC Public Health. 2020;20(1):610. https://doi.org/10.1186/s12889-020-08758-7.

4. Dellinger RP, Levy MM, Rhodes A, Annane D, Gerlach H, Opal SM, et al. Surviving Sepsis campaign: international guidelines for management of severe sepsis and septic shock, 2012. Intensive Care Med. 2013;39(2):165228. https://doi.org/10.1007/s00134-012-2769-8.

5. Rudd KE, Johnson SC, Agesa KM, Shackelford KA, Tsoi D, Kievlan DR, et al. Global, regional, and national sepsis incidence and mortality, 1990-2017: analysis for the global burden of disease study. Lancet. 2020;395(10219): 200-11. https://doi.org/10.1016/S0140-6736(19)32989-7.

6. Groves CP, Butland BK, Atkinson RW, Delaney AP, Pilcher DV. Intensive care admissions and outcomes associated with short-term exposure to ambient air pollution: a time series analysis. Intensive Care Med. 2020;46(6):1213-21. https://doi.org/10.1007/s00134-020-06052-z.

7. Rush B, Wiskar K, Fruhstorfer C, Celi LA, Walley KR. The impact of chronic ozone and particulate air pollution on mortality in patients with Sepsis across the United States. J Intensive Care Med. 2020;35(10):1002-7.

8. Sarmiento EJ, Moore JX, McClure LA, Griffin R, Al-Hamdan MZ, Wang HE. Fine particulate matter pollution and risk of community-acquired sepsis. Int J Environ Res Public Health. 2018;15(4):818.

9. Zhang Q, Streets DG, Carmichael GR, He K, Huo H, Kannari A, et al. Asian emissions in 2006 for the NASA INTEX-B mission. Atmos Chem Phys Discuss. 2009;9(14):5131-53. https://doi.org/10.5194/acp-9-5131-2009.

10. Zhang X, Wang Y, Niu T, Zhang X, Gong S, Zhang Y, et al. Atmospheric aerosol compositions in China: spatial/temporal variability, chemical signature, regional haze distribution and comparisons with global aerosols. Atmos Chem Phys Discuss. 2011;11:26571-615.

11. Singer M, Deutschman CS, Seymour CW, Shankar-Hari M, Annane D, Bauer $M$, et al. The third international consensus definitions for Sepsis and septic shock (Sepsis-3). JAMA. 2016;315(8):801-10. https://doi.org/10.1001/jama.201 6.0287 .

12. Iwashyna TJ, Odden A, Rohde J, Bonham C, Kuhn L, Malani P, et al. Identifying patients with severe sepsis using administrative claims: patientlevel validation of the angus implementation of the international consensus conference definition of severe sepsis. Med Care. 2014;52(6):e39-43. https:// doi.org/10.1097/MLR.0b013e318268ac86.

13. Wang Y, Yao C, Xu C, Zeng X, Zhou M, Lin Y, et al. Carbon monoxide and risk of outpatient visits due to cause-specific diseases: a time-series study in Yichang, China. Environ Health. 2019;18(1):36. https://doi.org/10.1186/s1294 0-019-0477-3.

14. Cai J, Zhao A, Zhao J, Chen R, Wang W, Ha S, et al. Acute effects of air pollution on asthma hospitalization in Shanghai, China. Environ Pollut. 2014; 191:139-44. https://doi.org/10.1016/j.envpol.2014.04.028.

15. Yao C, Wang Y, Williams C, Xu C, Kartsonaki C, Lin Y, et al. The association between high particulate matter pollution and daily cause-specific hospital admissions: a time-series study in Yichang, China. Environ Sci Pollut Res Int. 2020;27(5):5240-50.

16. Tian Y, Liu H, Liang T, Xiang X, Li M, Juan J, et al. Ambient air pollution and daily hospital admissions: a nationwide study in 218 Chinese cities. Environ Pollut. 2018;242(Pt B):1042-9.

17. Yin P, He G, Fan M, Chiu KY, Fan M, Liu C, et al. Particulate air pollution and mortality in 38 of China's largest cities: time series analysis. BMJ. 2017;356:j667.

18. Cheng J, Xu Z, Zhang X, Zhao H, Hu W. Estimating cardiovascular hospitalizations and associated expenses attributable to ambient carbon monoxide in Lanzhou, China: scientific evidence for policy making. Sci Total Environ. 2019;682:514-22. https://doi.org/10.1016/j.scitotenv.2019.05.110.

19. Bhaskaran K, Gasparrini A, Hajat S, Smeeth L, Armstrong B. Time series regression studies in environmental epidemiology. Int J Epidemiol. 2013; 42(4):1187-95. https://doi.org/10.1093/ije/dyt092.

20. Barnett AG, Stephen D, Huang C, Wolkewitz M. Time series models of environmental exposures: good predictions or good understanding. Environ Res. 2017;154:222-5. https://doi.org/10.1016/j.envres.2017.01.007.

21. Liu C, Chen R, Sera F, Vicedo-Cabrera AM, Guo Y, Tong S, et al. Ambient particulate air pollution and daily mortality in 652 cities. N Engl J Med. 2019; 381(8):705-15. https://doi.org/10.1056/NEJMoa1817364.

22. Li Z, Mao X, Liu Q, Song H, Ji Y, Xu D, et al. Long-term effect of exposure to ambient air pollution on the risk of active tuberculosis. Int J Infect Dis. 2019; 87:177-84. https://doi.org/10.1016/j.jijid.2019.07.027.

23. Nhung N, Amini H, Schindler C, Kutlar JM, Dien TM, Probst-Hensch N, et al. Short-term association between ambient air pollution and pneumonia in children: a systematic review and meta-analysis of time-series and casecrossover studies. Environ Pollut. 2017;230:1000-8. https://doi.org/10.1016/j. envpol.2017.07.063.

24. Tian Y, Liu H, Wu Y, Si Y, Li M, Wu Y, et al. Ambient particulate matter pollution and adult hospital admissions for pneumonia in urban China: a 
national time series analysis for 2014 through 2017. PLoS Med. 2019;16(12): e1003010. https://doi.org/10.1371/journal.pmed.1003010.

25. Nhung N, Schindler C, Dien TM, Probst-Hensch N, Perez L, Kunzli N. Acute effects of ambient air pollution on lower respiratory infections in Hanoi children: an eight-year time series study. Environ Int. 2018;110:139-48. https://doi.org/10.1016/j.envint.2017.10.024.

26. Li A, Fan L, Xie L, Ren Y, Li L. Associations between air pollution, climate factors and outpatient visits for eczema in West China hospital, Chengdu, South-Western China: a time series analysis. J Eur Acad Dermatol Venereol. 2018;32(3):486-94. https://doi.org/10.1111/jdv.14730.

27. Wei Y, Wang Y, Di Q, Choirat C, Wang Y, Koutrakis P, et al. Short term exposure to fine particulate matter and hospital admission risks and costs in the Medicare population: time stratified, case crossover study. BMJ. 2019; 367:16258

28. Scapellato ML, Lotti M. Short-term effects of particulate matter: an inflammatory mechanism? Crit Rev Toxicol. 2007;37(6):461-87. https://doi. org/10.1080/10408440701385622.

29. Khafaie MA, Salvi SS, Ojha A, Khafaie B, Gore SS, Yajnik CS. Systemic inflammation (C-reactive protein) in type 2 diabetic patients is associated with ambient air pollution in Pune City, India. Diabetes Care. 2013;36(3): 625-30. https://doi.org/10.2337/dc12-0388

\section{Publisher's Note}

Springer Nature remains neutral with regard to jurisdictional claims in published maps and institutional affiliations.

Ready to submit your research? Choose BMC and benefit from:

- fast, convenient online submission

- thorough peer review by experienced researchers in your field

- rapid publication on acceptance

- support for research data, including large and complex data types

- gold Open Access which fosters wider collaboration and increased citations

- maximum visibility for your research: over $100 \mathrm{M}$ website views per year

At BMC, research is always in progress.

Learn more biomedcentral.com/submissions 